\title{
STUDI EFEKTIFITAS DAN KINERJA INSTALASI PENGOLAHAN AIR LIMBAH (IPAL) PADA PETERNAKAN SAPI SKALA RUMAH TANGGA
}

\author{
Yunita Kusuma Bintang ${ }^{1}$, Dian Chandrasasi ${ }^{1}$, Riyanto Haribowo ${ }^{1}$ \\ ${ }^{1}$ Jurusan Teknik Pengairan Fakultas Teknik Universitas Brawijaya \\ e-mail: yunitaakusumabintang@gmail.com
}

\begin{abstract}
ABSTRAK: Desa Argosari merupakan salah satu desa yang memiliki peternakan sapi di Kabupaten Malang. Penelitian ini dilakukan di salah satu rumah di Desa Argosari dan memiliki 6 (enam) ekor sapi. Dalam satu hari tiap ekor sapi menghasilkan limbah cair sebesar 100-150 liter. Namun, limbah cair tersebut langsung dibuang ke saluran drainase karena belum adanya usaha dalam pengolahan limbah cair. Pada hasil uji laboratorium sampel air limbah, kandungan $\mathrm{BOD}, \mathrm{COD}, \mathrm{TSS}, \mathrm{NH}_{3}-\mathrm{N}$ dan $\mathrm{pH}$ pada influent limbah cair sapi masingmasing sebesar $4488 \mathrm{mg} / \mathrm{L}, 11000 \mathrm{mg} / \mathrm{L}, 850,5 \mathrm{mg} / \mathrm{L}, 479,3 \mathrm{mg} / \mathrm{L}, 8,5 \mathrm{mg} / \mathrm{L}$. Berdasarkan Peraturan Menteri Negara Lingkungan Hidup Nomor 11 Tahun 2009, kandungan limbah cair tersebut belum memenuhi standar baku mutu. Sehingga dibutuhkan Instalasi Pengolahan Air Limbah (IPAL) untuk dapat mengurangi kandungan pada limbah cair sapi. Instalasi yang sesuai pada kondisi tersebut adalah bak pengendap awal, bak biofilter aerob dan bak pengendap akhir. Biofilter aerob digunakan agar kandungan limbah cair dapat terurai secara biologis dengan menggunakan media biofilter sarang tawon untuk tempat tumbuh dan berkembangbiaknya mikroorganisme. Setelah adanya proses pengolahan IPAL, terjadi penurunan pada effluent, sehingga IPAL menghasilkan effluent BOD sebesar $80,78 \mathrm{mg} / \mathrm{L}$, $\mathrm{COD}=198 \mathrm{mg} / \mathrm{L}, \mathrm{TSS}=5,10 \mathrm{mg} / \mathrm{L}, \mathrm{NH}_{3}-\mathrm{N}=23,9 \mathrm{mg} / \mathrm{L}$ dan $\mathrm{pH}=8,5$.
\end{abstract}

Kata kunci: limbah cair sapi, bak biofilter aerob sarang tawon, IPAL

ABSTRACT: Argosari Village is one of the villages that has cattle farms in Malang Regency. This research was conducted in one of the houses in Argosari Village and has 6 (six) of cows. In one day, each cow produces 100-150 liters of liquid waste. However, the liquid waste is immediately discharged into the drainage channel because there is no effort to process wastewater. On the results of laboratory tests, samples of wastewater, BOD, COD, $\mathrm{TSS}, \mathrm{NH}_{3}-\mathrm{N}$ and $\mathrm{pH}$ in wastewater were respectively $4488 \mathrm{mg} / \mathrm{L}, 11000 \mathrm{mg} / \mathrm{L}, 850,5 \mathrm{mg} / \mathrm{L}$, $479,3 \mathrm{mg} / \mathrm{L}, 8,5 \mathrm{mg} / \mathrm{L}$. Based on the Regulation of the Minister of Environment Number 11 of 2009, the liquid waste has not met the quality standard. Wastewater Treatment Plant (WWTP) is needed to save reserves on cattle wastewater. The suitable installation in this condition is an initial settling basin, aerobic biofilter basin and a final settling basin. Aerobic biofilter is used so that liquid waste can be used biologically by using the media of honeycomb biofilter to grow and breed microorganisms. After processing the WWTP, there is a decrease in effluent, so WWTP can produce effluent BOD of $80,78 \mathrm{mg} / \mathrm{L}, C O D=198 \mathrm{mg} / \mathrm{L}, \mathrm{TSS}=$ $5,10 \mathrm{mg} / \mathrm{L}, \mathrm{NH}_{3}-\mathrm{N}=23,9 \mathrm{mg} / \mathrm{L}$ and $\mathrm{pH}=8,5$.

Key words: cattle wastewater, honeycomb biofilter basin, WWTP

Usaha peternakan sapi merupakan salah satu usaha yang harus diperhatikan karena limbah yang dihasilkan dapat menyebabkan pencemaran apabila tidak melalui proses pengolahan. Menurut data yang diperoleh badan statistik pada tahun 2017 terdapat 35 perusahaan budidaya ternak sapi atau sekitar 41,416 ekor. Limbah ternak sapi tersebut yaitu limbah padat (solid waste) yang terdiri dari feses dan sisa pakan (Merkel, 1981). Dan 
limbah cair (liquid waste) yang merupakan seluruh air yang digunakan, yaitu air untuk mencuci sapi, pembersihan kandang dan urin sapi.

Pencemaran air yang disebabkan oleh limbah cair sapi sering terjadi karena limbah cair langsung dibuang ke saluran drainase/sungai tanpa pengolahan terlebih dahulu. Pada umumnya limbah cair tersebut masih mengandung bahan organik tinggi. Selain pencemaran air, bau yang dihasilkan dari limbah sapi juga sangat buruk dan dapat mengganggu kenyamanan masyarakat.

Menurut peraturan Menteri Negara Lingkungan Hidup Nomor 11 Tahun 2009 tentang Baku Mutu Air Limbah bagi Usaha dan/atau Kegiatan Peternakan Sapi dan Babi, parameter yang harus diperhatikan yaitu BOD, COD, TSS, $\mathrm{NH}_{3}-\mathrm{N}$ dan $\mathrm{pH}$. Sehingga kualitas limbah cair yang dihasilkan harus sesuai standar yang telah ditentukan (Tefa et al, 2018).

Dalam satu hari setiap ekor sapi menghasilkan limbah cair sebanyak 100-150 liter (Saputro, 2014). Menurut Sutopo (2000), jumlah urin yang dikeluarkan satu ekor sapi dengan berat rata-rata $400 \mathrm{~kg}$ sebanyak 15 liter/hari. Desa Argosari merupakan salah satu desa yang memiliki peternakan sapi di Kabupaten Malang. Pada peternakan di Desa Argosari, para peternak sudah memanfaatkan limbah padat sapi sebagai biogas. Tetapi untuk limbah cair sapi masih dibuang secara langsung di saluran drainase/sungai.

Oleh karena itu diperlukan instalasi pengolahan air limbah (IPAL) untuk mengolah limbah cair sapi agar tidak terjadi pencemaran secara terus-menerus. Dalam perencanaan ini akan digunakan proses pengolahan secara biologis yaitu biofilter aerob. Pengolahan dengan biofilter aerob dinilai memiliki efisiensi yang besar untuk menghilangkan beban pencemar yang terkandung dalam air limbah karena adanya pertumbuhan dan perkembangan dari mikroorganisme dan supply udara. Pada perencanaan pengolahan ini juga menggunakan bak pengendap awal dan pengendap akhir untuk membantu proses pengolahan.

Tujuan dari penelitian ini untuk mendapatkan desain instalasi pengolahan air limbah (IPAL) yang sesuai untuk limbah cair sapi di Desa Argosari. Dan diharapkan untuk melakukan pengolahan agar limbah cair sapi yang dibuang memenuhi baku mutu yang ditetapkan dan tidak terjadi pencemaran secara terus-menerus.

\section{METODOLOGI PENELITIAN Lokasi Studi}

Objek studi dilakukan di salah satu rumah warga yang merupakan ketua kelompok peternak sapi di Dusun Bendrong Desa Argosari Kecamatan Jabung Kabupaten Malang Jawa Timur. Desa Argosari merupakan salah satu Desa yang berada di Kecamatan Jabung dan memiliki 3 Dusun, yaitu Dusun Pateguhan, Dusun Genthong dan Dusun Bendrong. 


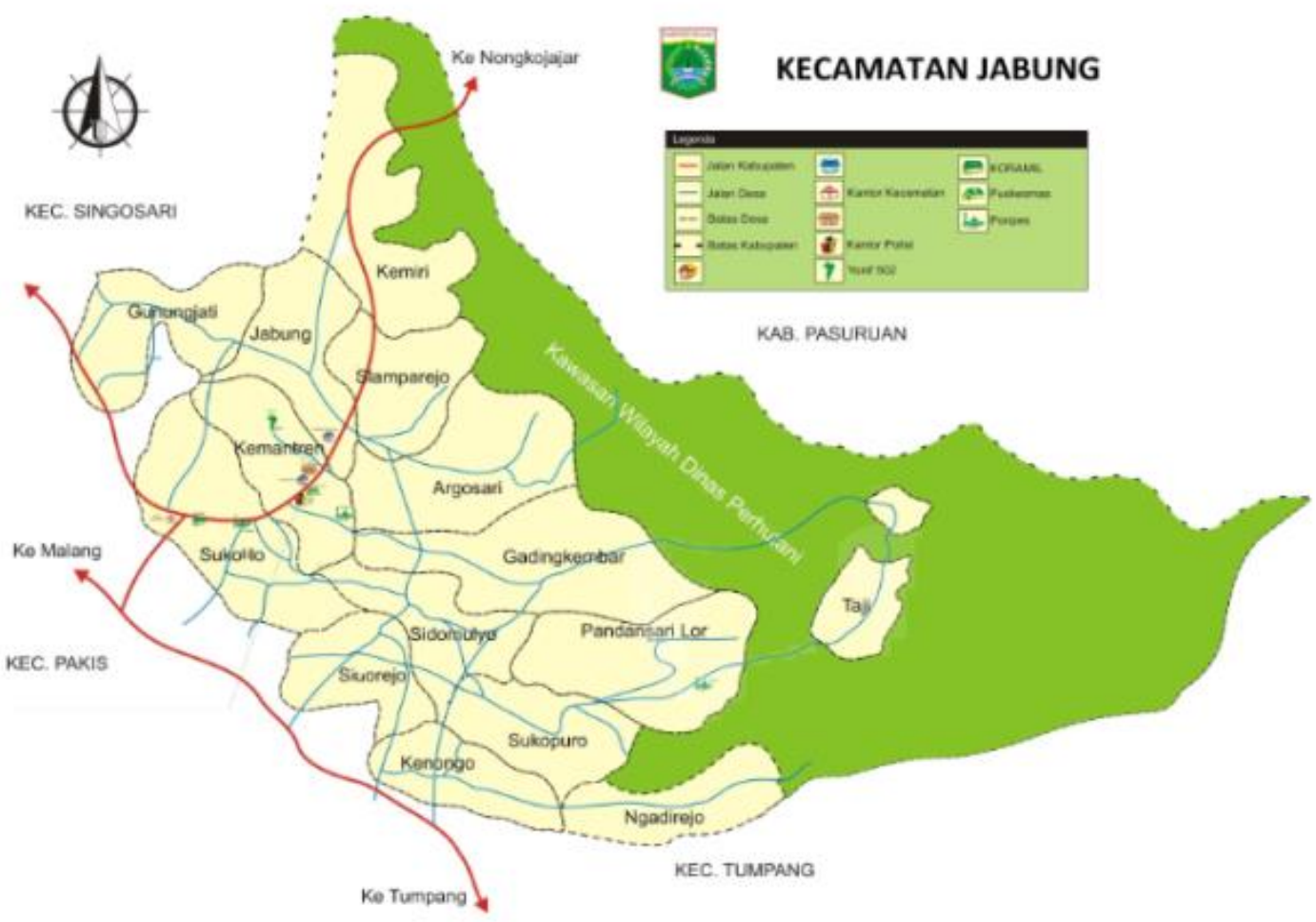

Gambar 1 Peta Kecamatan Jabung Kabupaten Malang Sumber: www. jabung.malangkab.go.id

\section{Data-Data yang Dibutuhkan}

1. Data jumlah hewan ternak sapi yang diperoleh dari pengamatan secara langsung.

2. Data kualitas air limbah cair hewan ternak sapi.

3. Data debit air limbah hewan ternak sapi yaitu debit limbah cair rerata untuk sapi perah dengan perhitungan berat badan sapi $400 \mathrm{~kg}$ yaitu 100-150 liter/ekor/hari. (Danang Dwi Saputro et al. 2014)

\section{Metode Analisa}

1. Pengumpulan data yang diperlukan, yaitu data jumlah hewan ternak sapi, data kualitas air limbah serta data debit air limbah.

- Data jumlah hewan ternak sapi dapat diambil dari pengamatan secara langsung dilokasi studi

- Data kualitas air dilakukan dengan mengambil sampel air limbah pada hari Minggu, 31 April 2019 secara grab sampling sesuai dengan SNI 6989.59:2008 tentang Air dan air limbah - Bagian 59. Kemudian sampel air limbah diuji di laboratorium dengan parameter $\mathrm{BOD}, \mathrm{COD}, \mathrm{TSS}, \mathrm{NH}_{3} \mathrm{~N}$ dan
pH. Data sampel air limbah tersebut kemudian dibandingankan dengan standar baku mutu air limbah sesuai Peraturan Menteri Negara Lingkungan Hidup Nomor 11 Tahun 2009 tentang Baku Mutu Air Limbah bagi Usaha dan/atau Kegiatan Peternakan Sapi dan Babi.

- Data debit air limbah didapat dari jurnal Danang Dwi Saputro et al. (2014) mengenai pengolahan limbah sapi yaitu debit limbah cair rerata untuk sapi perah dengan perhitungan berat badan sapi 400 kg yaitu 100-150 liter/ekor/hari.

2. Penentuan dan perhitungan desain instalasi pengolahan air limbah (IPAL) secara detail, mulai dari dimensi serta tahapan pengolahan yang sesuai dengan data-data yang ada.

3. Menghitung Rencana Anggaran Biaya (RAB) pembangunan instalasi pengolahan air limbah (IPAL).

\section{HASIL DAN PEMBAHASAN Perhitungan Debit Limbah Cair}

Pada umumnya, satu ekor sapi perah membutuhkan air bersih sekitar 200 liter/hari (Erif \& Bagus, 2011). Sedangkan kebutuhan 
sapi untuk minum yaitu sekitar 20-40 liter/ekor/hari (Syafrial et al. 2007) dan menghasilkan limbah cair urine sebesar 10-15 liter/ekor/hari (Hutwan Syarifudin et al. 2015). Menurut Danang Dwi Saputro et al. (2014), limbah cair satu ekor sapi sebesar 100150 liter/hari. Limbah cair yang dihasilkan dari membersihkan kandang dan memandikan tidak sebesar $100 \%$ dari kebutuhan air. Hal tersebut dikarenakan ada sebagian air yang menempel pada kulit sapi. Limbah cair sapi yang digunakan yaitu 150 liter/hari.

\section{Limbah cair total=limbah cair per-sapi x6} $=150$ liter/ekor/hari x 6

$$
\begin{aligned}
& =900 \text { liter/hari } \\
& =0,90 \mathrm{~m}^{3} / \text { hari } \\
& =0,038 \mathrm{~m}^{3} / \mathrm{jam}
\end{aligned}
$$

\section{Analisa Kualitas Air Limbah}

Analisa dilakukan guna memperoleh kualitas limbah cair yang dihasilkan dari peternakan sapi. Penentuan parameter uji sesuai menurut Peraturan Menteri Negara Lingkungan Hidup Nomor 11 Tahun 2009 dan analisa kualitas air limbah dilakukan di Laboratorium Perum Jasa Tirta I Malang. Metode dalam analisa disesuaikan kepada pihak laboratorium dengan SNI yang ada.

Tabel 1. Hasil Pengujian Kualitas Air Limbah Hewan Ternak Sapi

\begin{tabular}{cccc}
\hline Parameter & Satuan & Hasil Analisa & Standar Baku Mutu \\
\hline BOD & $\mathrm{mg} / \mathrm{L}$ & 4488 & 100 \\
$\mathrm{COD}$ & $\mathrm{mg} / \mathrm{L}$ & 11000 & 200 \\
$\mathrm{TSS}$ & $\mathrm{mg} / \mathrm{L}$ & 850,5 & 100 \\
$\mathrm{NH}_{3}-\mathrm{N}$ & $\mathrm{mg} / \mathrm{L}$ & 479,3 & 25 \\
$\mathrm{pH}$ & - & 8,5 & $6-9$ \\
\hline
\end{tabular}

Dari hasil analisa laboratorium pada Tabel 1, kandungan BOD pada air limbah sebesar $4488 \mathrm{mg} / \mathrm{L}$, COD sebesar 11000 $\mathrm{mg} / \mathrm{L}$, TSS sebesar 850,5 $\mathrm{mg} / \mathrm{L}, \quad \mathrm{NH}_{3}-\mathrm{N}$ sebesar 479,3 mg/L dan $\mathrm{pH}$ sebesar 8,5. Jika dibandingkan dengan standar baku mutu air limbah, kandungan BOD, COD, TSS, dan NH3-N masih melebihi batas standar baku mutu kualitas air limbah dan hanya $\mathrm{pH}$ yang sesuai.

\section{Penentuan Model IPAL}

Pada hasil laboratorium tentang analisa kualitas air sampel limbah cair hewan ternak sapi masih terdapat paramer yang tidak memenuhi standar baku mutu yang sudah ditentukan, sehingga diperlukan Instalasi Pengolahan Air Limbah (IPAL). Penentuan model IPAL harus disesuaikan pada kriteria model yang dibutuhkan pada lokasi studi dan diharapkan dapat mengurangi beban kontaminan pada air limbah cair hewan ternak sapi. Perencanaan Instalasi Pengolahan Air Limbah (IPAL) cair hewan ternak sapi pada studi ini menggunakan biofilter aerob. Berikut merupakan penjelasan dari model IPAL yang direncanakan (BPPT, 2010):

a) Limbah cair sapi dialirkan dari saluran outlet menuju ke bak pengendap awal. Bak pengendap awal digunakan untuk mengendapkan atau menghilangkan kotoran padat yang ada pada air limbah. Selain itu digunakan untuk bak kontrol aliran, pengurai dan penampung lumpur serta bak pengurai senyawa organik yang berbentuk padatan.

b) Selanjutnya air limbah akan dialirakan masuk ke bak biofilter aerob. Bak biofilter aerob pada pengolahannya berisi media biofilter bahan plastik tipe sarang tawon untuk tempat tumbuh dan berkembangbiaknya mikroorganisme dan diberikan supply udara.

c) Air limbah dari bak biofilter aerob, kemudian akan dialirkan menuju bak pengendap akhir. Bak pengendap akhir juga berfungsi untuk mengendapkan kotoran padat dan penampung lumpur serta bak pengurai senyawa organik yang berbentuk padatan yang belum sempat terurai pada bak sebelumnya ada pada air limbah dapat langsung dibuang ke sungai atau saluran drainase.

Pada gambar 2 merupakan skema dari perencanaan pengolahan limbah cair hewan ternak sapi yang terdiri dari bak pengendap awal, bak biofilter aerob dan bak pengendap akhir. 


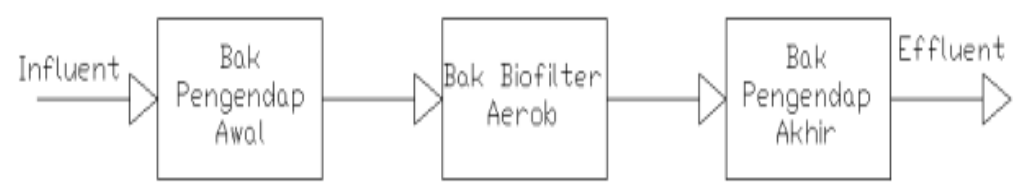

Gambar 2 Skema Pengolahan Limbah Cair Hewan Ternak Sapi

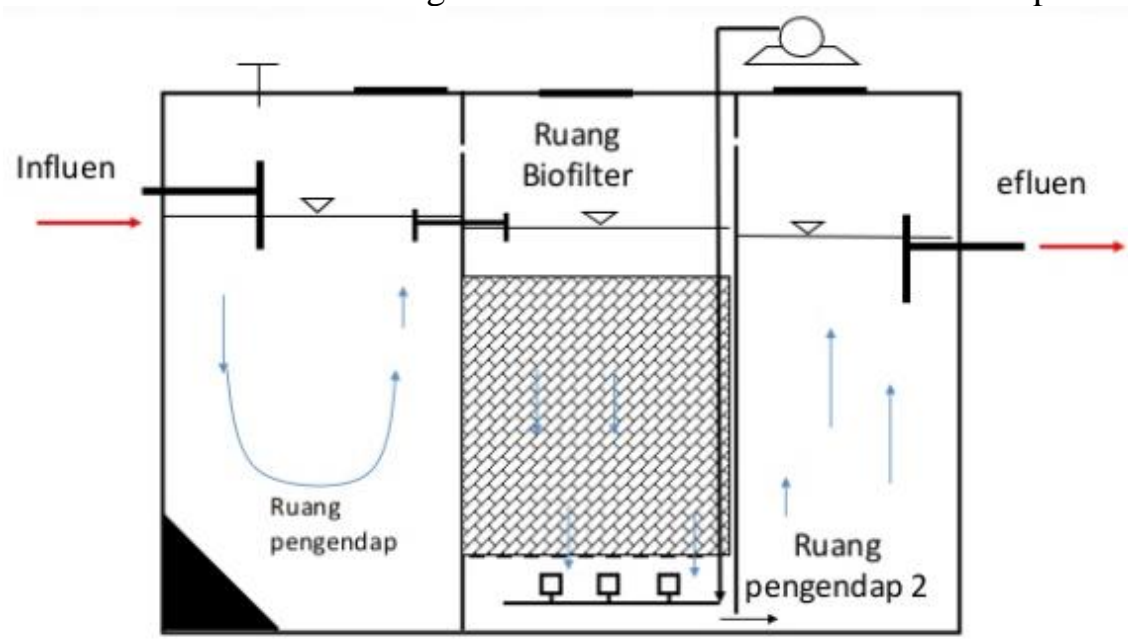

Gambar 3 Proses Pengolahan Air Limbah dengan Proses Biofilter Aerob Sumber: Imanputhra (2015)

Pada gambar 3 merupakan contoh proses pengolahan menggunakan biofilter aerob yang ditambah dengan supply udara dan media biofilter sarang tawon.

\section{Perencanaan dan Perhitungan Desain}

\section{- Bak Pengendap Awal}

a) Data

$$
\begin{aligned}
& \text { Debit }(\mathrm{Q}) \quad=0,90 \mathrm{~m} 3 / \text { hari } \\
& =0,038 \mathrm{~m} 3 / \mathrm{jam} \\
& \text { BOD masuk } \quad=4488 \mathrm{mg} / \mathrm{L} \\
& \text { COD masuk }=11000 \mathrm{mg} / \mathrm{L} \\
& \text { TSS masuk } \quad=850,5 \mathrm{mg} / \mathrm{L} \\
& \mathrm{NH}_{3}-\mathrm{N} \text { masuk }=479,3 \mathrm{mg} / \mathrm{L} \\
& \mathrm{pH} \text { masuk }=8,5 \mathrm{mg} / \mathrm{L} \\
& \text { b) Perhitungan } \\
& >\text { Direncanakan: } \\
& \text { Waktu tinggal }=5 \text { jam } \\
& >\text { Volume dan dimensi bak: } \\
& \text { Vdiperlukan }=\mathrm{Q} \times \mathrm{t} \\
& =0,038 \times 5 \\
& =0,19 \mathrm{~m}^{3} \\
& \text { Dimensi bak }=\mathrm{p} \times 1 \times \mathrm{t} \\
& =1 \mathrm{~m} \times 0,5 \mathrm{~m} \times 0,55 \mathrm{~m} \\
& =0,275 \mathrm{~m}^{3} \\
& \mathrm{t}=\frac{\text { Volume bak }}{\text { Debit limbah cair perjam }}
\end{aligned}
$$

$$
\begin{aligned}
& =\frac{0,275}{0,038} \\
& =7,3 \mathrm{jam}
\end{aligned}
$$

c) Penentuan Kualitas Effluent

Pada bak pengendapan awal direncanakan memiliki effisiensi pengurangan zat organik sebesar $70 \%$ TSS dan $40 \%$ xat organik. (Metcalf and Eddy, 1991)

$$
\begin{aligned}
\text { TSS keluar } & =30 \% \times \text { TSS masuk } \\
& =30 \% \times 850,5 \\
& =255,15 \mathrm{mg} / \mathrm{L} \\
\text { BOD keluar } & =60 \% \times \text { BOD masuk } \\
& =60 \% \times 4488 \\
& =2692,8 \mathrm{mg} / \mathrm{L} \\
\text { COD keluar } & =60 \% \times \mathrm{COD} \text { masuk } \\
& =60 \% \times 11000 \\
& =6600 \mathrm{mg} / \mathrm{L}
\end{aligned}
$$

- Bak Biofilter Aerob

a) Perhitungan

Perhitungan beban BOD dan COD

Beban $\mathrm{BOD}=$ beban BOD limbah cair urin + beban BOD limbah cair lain-lain $=0,2207 \mathrm{~kg} / \mathrm{hari}+0,1944$ $\mathrm{kg} / \mathrm{hari}$ $=0,415 \mathrm{~kg} / \mathrm{hari}$

Beban COD = beban COD limbah cair urin + beban COD limbah cair lain-lain 


$$
\begin{aligned}
& =0,551 \mathrm{~kg} / \mathrm{hari}+0,391 \\
& \mathrm{~kg} / \mathrm{hari} \\
& =0,942 \mathrm{~kg} / \mathrm{hari}
\end{aligned}
$$

Volume media yang diperlukan

Perhitungan volume media didasarkan besar beban BOD. Untuk pengolahan air dengan biofilter, standar beban BOD per volume media adalah 0,5-4 $\mathrm{kg} \mathrm{BOD} /$ $\mathrm{m}^{3}$.hari (BPPT, 2010). Ditetapkan dalam perhitungan beban BOD yang digunakan yaitu $1 \mathrm{~kg} \mathrm{BOD} / \mathrm{m}^{3}$.hari.

$\mathrm{V}$ media $=$ Beban BOD $/$ Standar BOD

$$
\begin{aligned}
& =0,415 \mathrm{~kg} / \text { hari } / 1 \mathrm{~kg} / \mathrm{m}^{3} / \text { hari } \\
& =0,415 \mathrm{~m}^{3}
\end{aligned}
$$

Volume reaktor yang diperlukan

Menurut Dep. PU, Pd-T-04-2005-C, volume media biofilter sebesar $55 \%$ dari volume reaktor, maka:

$\mathrm{V}$ reaktor $=(100 / 55) \mathrm{x}$ volume media

$$
=(100 / 55) \times 0,415 \mathrm{~m}^{3}
$$$$
=0,755 \mathrm{~m}^{3}
$$

Waktu tinggal di dalam reaktor

$$
\mathrm{t}=\frac{\text { Volume bak }}{\text { Debit limbah cair perjam }}
$$$$
=\frac{0,755}{0,038}
$$$$
=20,13 \mathrm{jam}
$$

$>$ Dimensi Bak Biofilter Aerob

Dimensi bak $=\mathrm{p} \times 1 \times \mathrm{t}$

$$
\begin{aligned}
& =1 \mathrm{m \times} 0,6 \mathrm{~m} \times 1,3 \mathrm{~m} \\
& =0,78 \mathrm{~m}^{3}
\end{aligned}
$$

Tinggi jagaan $=0,3 \mathrm{~m}$

$>$ Waktu tinggal reaktor aerob rata-rata

$\mathrm{t}=$ Volume bak/Debit limbah cair

$=0,78 / 0,038$

$=20,8 \mathrm{jam}$

Cek beban BOD per volume media biolfiter

Beban BOD =Beban BOD/Volume media

$$
=0,415 / 0,78
$$$$
=0,532 \mathrm{KgBOD} / \mathrm{m}^{3} \text {.hari }
$$

Jumlah media biofilter aerob

Berdasarkan ukuran yang tersedia di pasaran, satu buah media sarang tawon tipe crossflow memiliki volume sebesar 0,36 $\mathrm{m}^{3}$ dengan dimensi standar yaitu $1,2 \mathrm{~m} \mathrm{x}$ $0,5 \mathrm{~m} \times 0,6 \mathrm{~m}$, maka jumlah yang diperlukan:

$\mathrm{n} \quad=$ Volume media/Volume satu buah media

$$
\begin{aligned}
& =0,78 / 0,36 \\
& =2,17 \text { buah } \sim 3 \text { buah }
\end{aligned}
$$

b) Blower Udara pada Biofilter Aerob

Kebutuhan oksigen (beban BOD) $=0,415$ $\mathrm{kg} / \mathrm{hari}$
Digunakan faktor keamanan (FS) sebesar 1,6 untuk packing berupa plastic cross flow (Metcalf and Eddy, 2003:905)

Kebutuhan oksigen $=$ FS $\mathrm{x}$ beban $\mathrm{BOD}$

$$
\begin{aligned}
& =1,6 \times 0,415 \\
& =0,664 \mathrm{~kg} / \mathrm{hari}
\end{aligned}
$$

Kebutuhan udara teoritis digunakan untuk menentukan kapasitas blower. Menurut Metcalf and Eddy, 2003:1738

Presentasi $\mathrm{O}_{2}$ dalam udara $=23,18 \%$

Suhu udara rerata $=30^{\circ} \mathrm{C}$

Massa jenis udara pada suhu $30^{\circ} \mathrm{C}$ :

$$
\mathrm{P} \alpha=\frac{\mathrm{P} \times \mathrm{M}}{\mathrm{R} \times \mathrm{T}}
$$

dengan,

$\mathrm{P}=1,01325.105 \mathrm{~N} / \mathrm{m} 2$

$\mathrm{M}=28,97 \mathrm{~kg} / \mathrm{kg} \cdot \mathrm{mol}$

$\mathrm{R}=8314 \mathrm{~N} \cdot \mathrm{m} / \mathrm{kg} \cdot \mathrm{mol} \cdot \mathrm{K}$

Sehingga:

$$
\begin{aligned}
\mathrm{P} \alpha & =\frac{\mathrm{P} \times \mathrm{M}}{\mathrm{R} \times \mathrm{T}} \\
& =\frac{1,01325 \times 10^{5} \times 28,97}{8314 \times(273,15+30)} \\
& =1,165 \mathrm{~kg} / \mathrm{m}^{3}
\end{aligned}
$$

Jumlah kebutuhan udara $=$ Kebutuhan oksigen/ $\mathrm{P} \alpha$

$$
\begin{aligned}
& =0,664 /(1,165 \times 23,1 \%) \\
& =2,469 \mathrm{~m} 3 / \text { hari }
\end{aligned}
$$

Kebutuhan udara aktual

Efisiensi udara 2,0\%

Keburuhan udara aktual =Jumlah

kebutuhan udara teoritis/ Efisiensi

$$
\begin{aligned}
& =2,469 / 0,02 \\
& =123,449 \mathrm{~m} 3 / \text { hari } \\
& =0,086 \mathrm{~m} 3 / \mathrm{menit} \\
& =85,728 \text { liter/menit }
\end{aligned}
$$

Direncanakan blower udara yang diperlukan degan spesifikasi sebagai berikut:

$$
\begin{aligned}
& \text { Kapasitas }=\max 190 \text { liter } / \text { menit } \\
& \text { Tekanan } \quad=6 \mathrm{kPa} \\
& \text { Jumlah } \quad=1 \text { unit } \\
& \text { Dimensi }=16,5 \mathrm{~cm} \times 20,5 \mathrm{~cm} \quad \mathrm{x} \\
& 21 \mathrm{~cm} \\
& \text { Daya } \quad=120 \text { watt } \\
& \text { Rekomendasi }=\text { Resun GF-120 } \\
& \text { Harga } \quad= \pm 939.000,-
\end{aligned}
$$

c) Penentuan Kualitas Effluent

Pada bak biofilter aerob direncanakan memiliki effisiensi pengurangan zat organik sebesar 95\% (Said, 1999)

$$
\begin{aligned}
\text { TSS keluar } & =5 \% \times \text { TSS masuk } \\
& =5 \% \times 255,15 \\
& =12,758 \mathrm{mg} / \mathrm{L} \\
\text { BOD keluar } & =5 \% \times \text { BOD masuk } \\
& =5 \% \times 2692,8
\end{aligned}
$$




$$
\begin{aligned}
& =134,64 \mathrm{mg} / \mathrm{L} \\
\text { COD keluar } & =5 \% \times \mathrm{COD} \text { masuk } \\
& =5 \% \times 6600 \\
& =330 \mathrm{mg} / \mathrm{L} \\
\mathrm{NH}_{3}-\mathrm{N} \text { keluar } & =5 \% \times \mathrm{NH}_{3}-\mathrm{N} \text { masuk } \\
& =5 \% \times 479,3 \\
& =23,96 \mathrm{mg} / \mathrm{L}
\end{aligned}
$$

\section{- Bak Pengendap Akhir}

a) Perhitungan

$>$ Direncanakan:

Waktu tinggal $=5$ jam

$>$ Volume dan dimensi bak:

Vdiperlukan $=\mathrm{Q} \times \mathrm{t}$

$=0,038 \times 5$

$=0,19 \mathrm{~m}^{3}$

Dimensi bak $=\mathrm{p} \times 1 \times \mathrm{t}$

$=1 \mathrm{~m} \times 0,5 \mathrm{~m} \times 0,55 \mathrm{~m}$

$=0,275 \mathrm{~m}^{3}$

Tinggi jagaan $=0,3 \mathrm{~m}$

Perhitungan waktu tinggal

$\mathrm{t}=\frac{\text { Volume bak }}{\text { Debit limbah cair perjam }}$ $=\frac{0,275}{0,038}$

$$
=7,3 \mathrm{jam}
$$

b) Penentuan Kualitas Effluent

Pada bak pengendapan akhir direncanakan memiliki effisiensi pengurangan zat organik sebesar $70 \%$ TSS dan $40 \%$ xat organik. (Metcalf and Eddy, 1991)

$$
\begin{aligned}
\text { TSS keluar } & =30 \% \times \mathrm{TSS} \text { masuk } \\
& =30 \% \times 12,75 \\
& =5,103 \mathrm{mg} / \mathrm{L} \\
\text { BOD keluar } & =60 \% \times \mathrm{BOD} \text { masuk } \\
& =60 \% \times 134,64 \\
& =80,784 \mathrm{mg} / \mathrm{L} \\
\text { COD keluar } & =60 \% \times \mathrm{COD} \text { masuk } \\
& =60 \% \times 330 \\
& =198 \mathrm{mg} / \mathrm{L}
\end{aligned}
$$

- Hasil Pengolahan (Effluent)

Perencanaan IPAL untuk limbah cair hewan ternak sapi yang terdiri dari bak pengendap awal, bak biofilter aerob dan bak pengendap akhir seperti pada gambar 4 menghasilkan Effluent yang dihasilkan dari proses pengolahan limbah cair sapi adalah sebagai berikut

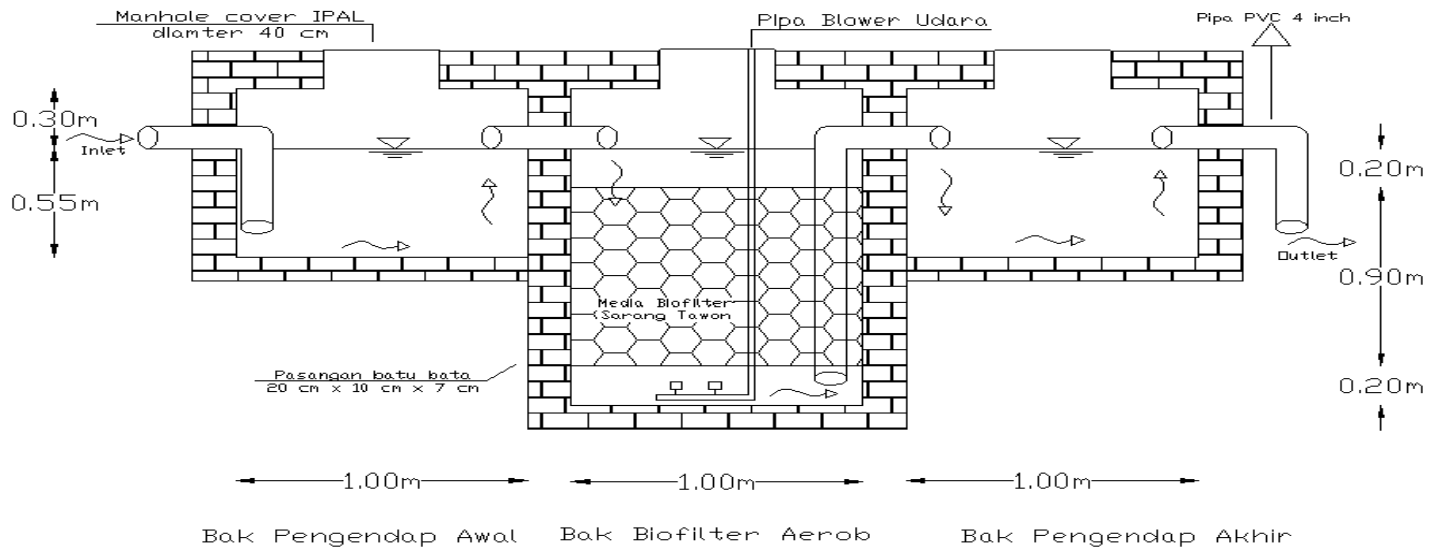

Gambar 4 Detail Gambar IPAL

Tabel 2. Kualitas Effluent Proses Pengolahan

\begin{tabular}{|c|c|c|c|c|c|}
\hline \multirow{2}{*}{ Section } & \multicolumn{4}{|c|}{ Parameter } \\
\cline { 2 - 5 } & BOD & COD & TSS & $\mathrm{NH}_{3}-\mathrm{N}$ & \multirow{2}{*}{$\mathrm{pH}$} \\
\cline { 2 - 5 } & $\mathrm{mg} / \mathrm{L}$ & $\mathrm{mg} / \mathrm{L}$ & $\mathrm{mg} / \mathrm{L}$ & $\mathrm{mg} / \mathrm{L}$ & \\
\hline Influent & 4488 & 11000 & 850,5 & 479,3 & \\
\hline Bak Pengendap Awal & $40 \%$ & $40 \%$ & $70 \%$ & $0 \%$ & \\
\hline Bak Biofilter Aerob & 2692,8 & 6600 & 255,15 & 479,3 & \\
\hline & $95 \%$ & $95 \%$ & $95 \%$ & $95 \%$ & \multirow{2}{*}{8,5} \\
\hline Bak Pengendap Akhir & 134,64 & 330 & 12,76 & 23,96 & \\
\hline & $40 \%$ & $40 \%$ & $70 \%$ & $0 \%$ & \\
\hline Effluent & 80,784 & 198 & 5,10 & 23,96 & \\
\hline
\end{tabular}

Tabel 3. Perbandingan Kualitas Air 


\begin{tabular}{|c|c|c|c|}
\hline Parameter & Baku Mutu & $\begin{array}{c}\text { Hasil Pengolahan IPAL } \\
\text { Rencana }\end{array}$ & Keterangan \\
\hline BOD & 100 & 80,78 & Memenuhi \\
\hline COD & 200 & 198 & Memenuhi \\
\hline TSS & 100 & 5,10 & Memenuhi \\
\hline NH3-N & 25 & 23,96 & Memenuhi \\
\hline pH & $6-9$ & 8,5 & Memenuhi \\
\hline
\end{tabular}

Berdasarkan Tabel 2 dan 3, effluent limbah cair hewan ternak sapi dapat berkurang setelah melalui proses pengolahan yang telah direncanakan dan telah memenuhi standar baku mutu air limbah pada Peraturan Menteri Negara Lingkungan Hidup Nomor 11 Tahun 2009.

\section{KESIMPULAN}

Berdasarkan hasil pembahasan, maka dapat diambil kesimpulan bahwa desain Instalasi Pengolahan Air Limbah (IPAL) yang sesuai dengan hasil kandungan pengujian sampel air limbah hewan ternak sapi yaitu dengan menggunakan bak pengendap awal, bak biofilter aerob dan bak pengendap akhir. Untuk bak pengendap awal menghasilkan volume rencana sebesar $0,275 \mathrm{~m}^{3}$. Kemudian bak biofilter aerob sebesar $0,78 \mathrm{~m}^{3}$ dan didalamnya terdapat media biofilter sarang tawon dan supply udara. Pada proses pengolahan terakhir terdapat bak pengendap akhir dengan volume $0,275 \mathrm{~m}^{3}$. Dengan proses pengolahan tersebut, diperkirakan kualitas effluent limbah cair hewan ternak sapi menjadi lebih baik dan memenuhi baku mutu yang sudah ditetapkan pemerintah.

\section{DAFTAR PUSTAKA}

Badan Standarisasi Nasional. 2008. Air dan Air Limbah- Bagian 59: Metoda Pengambilan Contoh Air Limbah. Tangerang: Badan Standarisasi Nasional

Direktorat Bina Pelayanan Penunjang Medik dan Sarana Kesehatan. (2011). Pedoman Teknis Instalasi Pengolahan Air Limbah dengan Sistem Biofilter Anaerob Aerob pada
Fasilitas Pelayanan Kesehatan. Jakarta: Kementerian Kesehatan RI

Tefa MA, Harisuseno D, Haribowo R. (2018). Potential use of aquatic plants in constructed wetlands for simultaneous removal of Phosphate and COD from laundry wastewater. Civil and Environmental Science Journal 1 (2), 70-79, 2018.

Metcalf, dan Eddy. (2003). Wastewater Engineering Treatment and Reuse Fourth Edition (International Edition). New York: McGraw-Hill

Peraturan Menteri Negara Lingkungan Hidup Nomor 11 Tahun 2009 tentang Baku Mutu Air Limbah bagi Usaha dan/atau Kegiatan Peternakan Sapi dan Babi.

Said, Nusa Idaman. (1991). Teknologi Pengolahan Limbah Cair Industri. Jakarta: Pusat Teknologi Lingkungan

Saputro, Danang Dwi., Burhan Rubai \& Yuni Wijayanti. (2014). Pengelolaan Limbah Peternakan Sapi Untuk Meningkatkan Kapasitas Produksi Pada Kelompok Ternak Patra Sutera, Jurnal Rekayasa. 12 (II): 1-8

Syarif, Erif Kemal \& Bagus Harianto. (2011). Buku Pintar Beternak \& Bisnis Sapi Perah. Jakarta Selatan: AgroMedia Pustaka

Syafrial, dkk. (2007). Manajemen Pengelolaan Penggemukan Sapi Potong. Jambi: Balai Pengkajian Teknologi Pertanian Jambi

Syarifuddin, Hutwan., M. Ridwan. \& Suryadi. (2015). IbM Aplikasi Teknologi Feurinsa Menuju Peternakan Ramah Lingkungan. Jurnal Pengabdian Masyarakat. 30 (IV): 61-69. 